\title{
A Dimensáo da Deficiência e o Olhar a Respeito das Pessoas com Deficiência a Partir dos Recenseamentos no Brasil
}

\author{
The Disability Dimension and VieW of People With Disabilities from the \\ CENSUSES IN BRAZIL
}

\author{
José Roberto Herrera CANTORANI ${ }^{1}$ \\ Leandro Martinez VARGAS ${ }^{2}$ \\ Paulo Eduardo REDKVA ${ }^{3}$ \\ Luiz Alberto PILATTI ${ }^{4}$ \\ Gustavo Luis GUTIERREZ ${ }^{5}$
}

\begin{abstract}
RESUMO: o olhar a respeito das pessoas com deficiência tem se alterado ao longo dos anos. O mesmo tem ocorrido com os números e percepçóes que retratam a dimensão da deficiência. O objetivo deste estudo é identificar essas mudanças a partir dos instrumentos de levantamento populacional. Para isso, acompanhou-se a evoluçáo da abordagem dada à deficiência, tanto em relação ao foco, quanto à base conceitual dos referidos instrumentos. Para esta análise foram estudados os Recenciamentos realizados no período de 1872 à 2010, e as Pesquisas Nacionais por Amostra de Domicílios realizadas entre 1981 e 2003. Verificou-se que as mudanças operacionalizadas nos recenseamentos acompanharam a evolução conceitual da deficiência. Essa mudança de olhar também acabou mostrando que o universo das deficiências é bem mais amplo que anteriormente se enxergava. E mostra também que a sociedade é responsável, ao não se adequar às desigualdades, pela criação social da deficiência, em torno de 45.606.048 milhốes de pessoas, o que corresponde a 23,9\% da população brasileira.
\end{abstract}

PALAVRAS-CHAVE: Educação Especial. Processo de Integração Social. Documentos Oficiais. Realidade Social.

\begin{abstract}
Views about people with disabilities have changed over the years. The same has occurred with the numbers and perceptions that portray the disability dimension. The aim of this study is to identify these changes using population survey instruments. To this end, we followed how the ways disability of approaching have changed over time, regarding focus, as the conceptual basis of these instruments. For this analysis the censuses during the period from 1872 to 2010 and the National Household Sample Surveys conducted between 1981 and 2003 were studied. It was found that changes in censuses followed the conceptual evolution of disability. This change of view also shows that the universe of disability is much broader than previously conceived. The results also show that society, by not considering inequalities, is responsible, for the social creation disability, encompassing approximately 45.606 .048 million people, which accounts for $23.9 \%$ of the population.
\end{abstract}

KEYWORDS: Special education. Social Integration Process. Official Documents. Social Reality.

\section{INTRODUÇÃo}

O debate sobre deficiência tem ocupado um espaço cada vez mais privilegiado no cenário internacional e brasileiro, tanto no palco das investigaçóes científicas como no das políticas públicas. Em decorrência desta atenção ao tema "deficiência" é verificado avanços

${ }^{1}$ Doutorando pela Universidade Estadual de Campinas, Faculdade de Educação Física, Área de Concentração: Atividade Física Adaptada. Coordenador do Curso de Educação Física das Faculdades Integradas de Itararé. Itararé, SP, Brasil. cantorani@yahoo.com.br

${ }^{2}$ Doutorando pela Universidade Estadual de Campinas, Faculdade de Educação Física, Área de Concentração: Atividade Física Adaptada. Professor do Curso de Educação Física das Faculdades Integradas de Itararé. Itararé, SP, Brasil.leandro.vargas@uol.com.br

${ }^{3}$ Mestre pela Universidade Federal do Paraná, Faculdade de Educação Física. Professor do Curso de Educação Física das Faculdades Integradas de Itararé. Itararé, SP, Brasil.pauloredkva@hotmail.com

${ }^{4}$ Doutor pela Universidade Estadual de Campinas, Faculdade de Educação Física. Professor da Universidade Tecnológica Federal do Paraná. Curitiba, PR, Brasil. luiz.pilatti@terra.com.br

${ }^{5}$ Professor Titular. Universidade Estadual de Campinas, Faculdade de Educação Física. Campinas, SP, Brasil. glgutierrez@terra.com.br 
conceituais, de trato metodológico e prático a respeito do referido objeto. Este avanço pode, inclusive, ser verificado nos recenseamentosrealizados no Brasil

Os primeiros levantamentos a respeito da população com deficiência no Brasil foram realizados ainda remotamente. As pesquisas nacionais que se ocuparam com levantamentos acerca das pessoas com deficiência foram os Recenseamentos de 1872, último Censo realizado na monarquia, 1900, 1920, 1940, 1991, 2000 e 2010 e também a Pesquisa Nacional por Amostra de Domicílios (PNAD) do ano de 1981, 1998 e 2003.

No ano de 1890 foi realizado um Censo em que foi abordado o conteúdo das deficiências. Contudo, os dados a respeito deste conteúdo não foram publicados em nível nacional. Menção a este respeito é encontrada no Censo de 1920 (BRASIL, 1928). No entanto, há referência de publicação destes dados apenas para algumas capitais, como no caso do distrito Federal do Brasil, na época o Rio de Janeiro. Números relativos a estes dados podem ser encontrados no Recenseamento de 1920, em publicação específica do Rio de Janeiro (BRASIL, 1923).

Olhar para estes levantamentos permite enxergar a evolução dos números representativos das pessoas com deficiência no Brasil. E permite também identificar mudanças de olhar e de atenção em relação a este grupo de pessoas. Essa identificação de mudanças é verificada nas estimativas oficiais e também na evolução dos instrumentos de coleta.

\section{Modelo SOCIAL DAS DEFICIÊNCIAS}

É importante para este estudo o destaque inicial ao modelo social das deficiências. O modelo social da deficiência estabelece-se na extensa discussão sobre políticas de bem-estar e de justiçasocial, para a qual a explicação médica para a desigualdade verificada nas pessoas com deficiência não é mais consideradasuficiente.

Conforme interpretam Medeiros e Diniz (2004), em análise ao modelo social da deficiência, seria possível uma pessoa ter lesões (limitaçóes) e não experimentar a deficiência, fato que dependeria de como/quanto a sociedade estaria ajustada para incorporar a diversidade. Desta forma, não poder caminhar é a expressão da imparidade; a deficiência consiste na inacessibilidade - encontrada na estrutura social - imposta às pessoas que não enxergam e que usam cadeira de rodas (MORRIS, 2001; MEDEIROS; DINIZ, 2004).

O resultado dessa revisão é a separação, ou, melhor dizendo, o entendimento da diferença semântica dos termos imparidade e deficiência e a depuração dos respectivos conceitos: o primeiro é posto como objeto de discussão na ordem da saúde, enquanto o segundo se constitui a partir da ordem dos direitos e da justiça social. Essa evoluçáo conceitual, de apreciação semântica e de diferenciação é fruto da participação efetiva, e cada vez maior, das pessoas com deficiência nas discussóes e tomadas de decisão daquilo que lhes diz respeito diretamente.

Não é porque estão fisicamente deficientes que são rejeitados pela sociedade, mas pela forma como as relaçóes sociais são organizadas. A deficiência não é algo que se possui, mas que é efetivada a partir da forma como a estrutura social é organizada. 
A apresentação dos dados que seguem visa a verificação da incorporação desta evolução conceitual aos instrumentos de pesquisa a respeito da deficiência e verificar a relação do número de pessoas com deficiência frente a esta evolução conceitual.

\section{Os RECENSEAMENTOS NO BRASIL E A ABORDAGEM ÀS DEFICIÊNCIAS}

Nos Recenseamentos Gerais de 1872, de 1900 e de 1920 levantou-se apenas o universo das pessoas com deficiência sensorial: os cegos e os chamados, à época, surdos-mudos (BRASIL, 1928). Os números referentes a estas condiçốes de deficiência estão apresentados na Tabela 1. Nesta tabela, os números se referem à quantidade de homens cegos ou surdos-mudos para cada 10.000 habitantes e também de mulheres cegas ou surdas-mudas para cada 10.000 habitantes.

Tabela 1 - Incidência de deficiência em número absoluto por 10.000 habitantes entre homens e mulheres.

\begin{tabular}{ccccccc}
\hline \multirow{2}{*}{ Anos } & \multicolumn{3}{c}{ Cegos } & \multicolumn{3}{c}{ Surdos-Mudos } \\
\cline { 2 - 7 } 1872 & Homens & Mulheres & Total & Homens & Mulheres & Total \\
1900 & 9,469 & 6,379 & 15,848 & 7,157 & 4,438 & 11,595 \\
1920 & 10,250 & 8,563 & 18,813 & 4,224 & 3,137 & 7,361 \\
\hline
\end{tabular}

Fonte: IBGE (1920).

A esta época, ainda não havia nenhum tipo de sensibilidade em relação às deficiências e às pessoas com deficiência. Buscava-se com o Censo levantar o número de pessoas com "defeitos físicos". Mas, importava naquele momento apenas os "defeitos" da visão e da audição.

No Censo Demográfico de 1940 o levantamento das deficiências ainda se limitou às deficiências sensoriais: cegos e surdos-mudos. No entanto, houve uma novidade em relação a esta investigação. O levantamento dos dados a respeito dos cegos foi acrescido da investigação da natureza dessas deficiências sensoriais.

A partir desta inovação foi possível verificar, conforme a Tabela 2, que das 60.701 pessoas que estavam em condição de cegueira, 64,5\% foram acometidas dessa deficiência em razão de doenças adquiridas ao longo da vida, enquanto que em $21 \%$ o acometimento se deu em razão de acidente e em 10,4\% por nascença. O Censo ainda levantou que 36.674 pessoas se encontravam na condição de surdos-mudos (IBGE, 1950).

Tabela 2 - Cegos e surdos-mudos, por sexo, com discriminação, para os cegos, da origem da deficiência.

\begin{tabular}{lcccccc}
\hline & \multicolumn{3}{c}{ Cegos } & \multicolumn{3}{c}{ Surdos-mudos } \\
\cline { 2 - 6 } & Total & Homens & Mulheres & Total & Homens & Mulheres \\
Totais & 60.701 & 31.281 & 29.420 & 36.674 & 19.442 & 17.232 \\
De Nascença & & 3.461 & 2.856 & & & \\
Por doença & & 18.977 & 20.207 & & & \\
Por acidente & & 7.657 & 5.060 & & & \\
Não declarada & & 1.069 & 1.195 & & & \\
\hline
\end{tabular}

Fonte: IBGE (1940). 
No que diz respeito à sensibilidade em relação às deficiências e às pessoas com deficiência não é possível dizer que houve mudança de fato. Contudo, um avanço se pronunciou, ainda que não se possa dizer que no sentido da sensibilidade. Este instrumento, além de levantar o número de pessoas com os "defeitos" da visão e da audição, buscou-se também verificar a causa.

Depois de 1940, nenhum outro Censo Demográfico abordou em seus levantamentos dados a respeito das pessoas com deficiência. Este levantamento somente apareceu novamente na Pesquisa Nacional por Amostra de Domicílio (PNAD) de 1981, a qual conferiu um avanço em relação ao Censo Demográfico de 1940. Neste levantamento, o universo das deficiências estabelecido para a pesquisa foi ampliado. A abrangência da pesquisa acerca das deficiências ficou assim estabelecida: cegueira, surdez, surdo-mudez, retardamento mental, falta de membro, paralisia total, paralisia de um dos lados do corpo, outro tipo de deficiência, mais de um tipo de deficiência. Contudo, a natureza das deficiências não foi levantada, como ocorreu no Censo de 1940. A PNAD de 1981 apurou que 1,7\% da população brasileira era constituída de pessoas com deficiência (NERI et al., 2003). A distribuição pode ser acompanhada no Gráfico 1, abaixo:

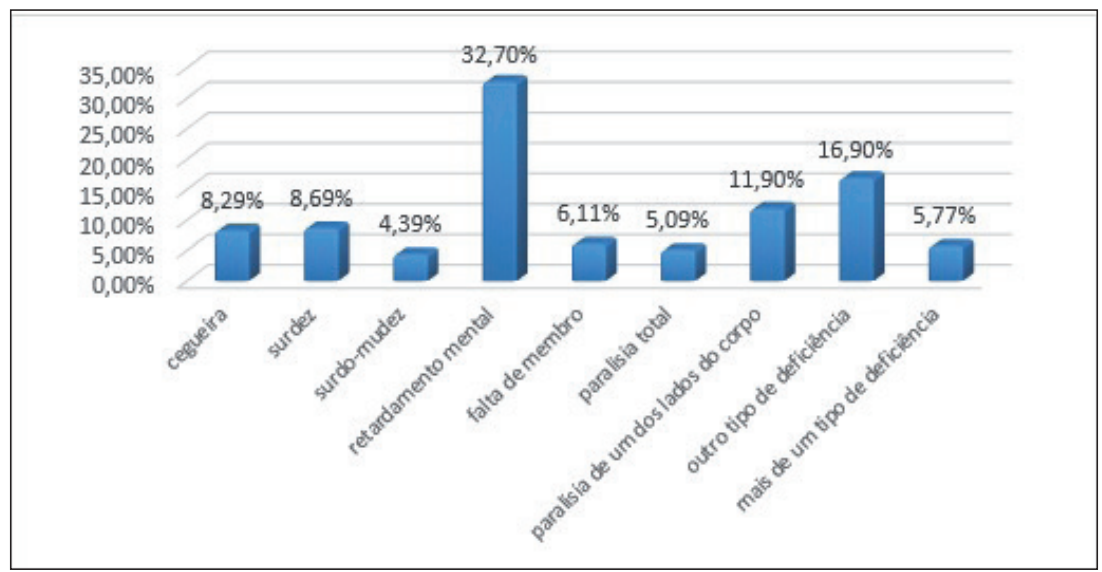

Gráfico 1 - Distribuição das deficiências em 1981 a partir do PNAD.

Fonte: CPS/FGV a partir dos microdados da PNAD 1981/IBGE (NERI et al., 2003).

Este instrumento ampliou o olhar a respeito das deficiências. Apesar de não ser ainda um olhar mais amplo, que foque os graus das limitaçóes, já se estabelece um levantamento de todas as deficiências graves.

No Censo Demográfico de 1991 foi retomada, novamente em um Censo, a investigação mais direta e objetiva a respeito das pessoas com deficiência. Este retorno em 1991 se deu em razão da promulgação da Lei no 7.853 de 24 de outubro de 1989, que prevê a obrigatoriedade de se incluir nos censos nacionais questóes específicas para as pessoas com deficiência (IBGE, 2004). O levantamento das deficiências foi realizado de forma semelhante ao que ocorreu na PNAD de 1981. A pesquisa para esta área, no Censo de 1991, levantou informações apenas das deficiências mais graves: cegueira, surdez, deficiência mental, falta de membro (s) ou parte dele, paralisia total, paralisia de um dos lados do corpo, paralisia nas pernas, mais de um tipo de deficiência - apenas no Censo de 2000 há um avanço significativo em relação à pesquisa para esta área. O Censo levantou que em 1991 o Brasil possuía aproximadamente 1,7 
milhão de pessoas com deficiência, o que correspondia à 1,15\% da população (IBGE, 1992; CHAGAS; VIOTTI, 2003). O número se mostrou inferior à 1981. A distribuição das deficiências pode ser acompanhada no Gráfico 2.

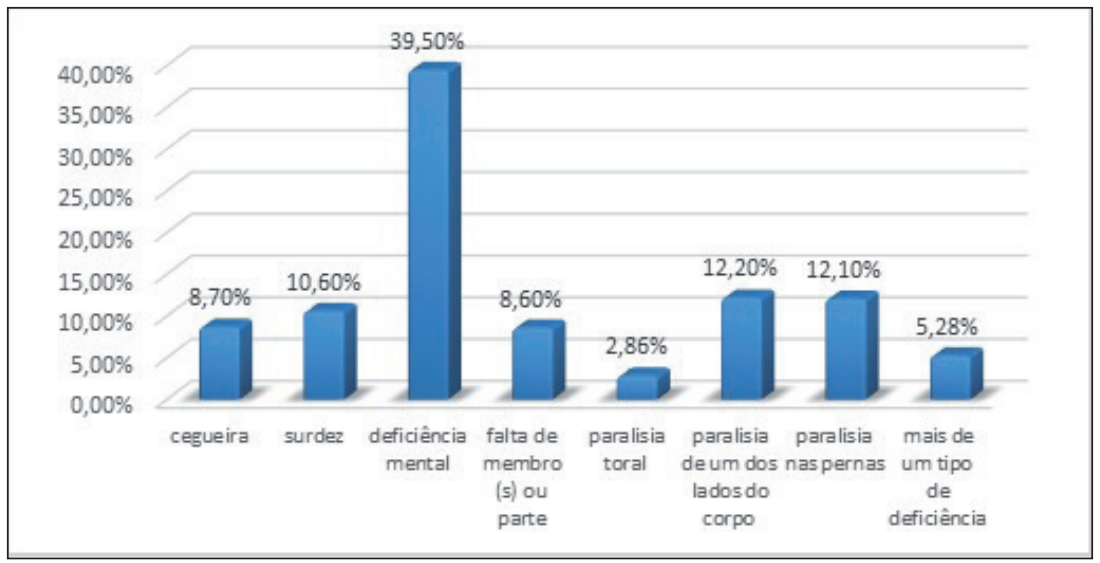

Gráfico 2 - Distribuição das deficiências em 1991 a partir do Censo Fonte: IBGE (1991).

Não houve nenhum avanço do Censo de 1991 em relação ao PNAD de 1981. O levantamento seguiu os parâmetros estabelecidos pela PNAD.

Para as PNADs de 1998 e 2003 foi elaborado um suplemento especial de saúde que abordou pontos referentes à capacidade funcional das pessoas para atividades físicas do dia-a-dia. Não é dada uma atenção às deficiências em sua forma estabelecida, mas, de forma indireta, é justificada uma aproximação para a identificação de pessoas com deficiência física, por meio da mobilidade e da restrição às atividades rotineiras por motivo de saúde (IBGE, 2000, 2005).

O Suplemento Saúde da PNAD 2003 apresenta uma relação entre os dados obtidos em 1998 e 2003 para a proporção de pessoas que manifestaram restrição à atividades rotineiras por motivo de saúde nas duas semanas anteriores à entrevista, com visualização no Gráfico 3. É avaliado ainda o nível de limitação para as atividades. Esta avaliação foi realizada por meio de um questionário que consiste em uma escala de limitação para as atividades diárias, composta por sete itens, apresentados no Quadro 1. 


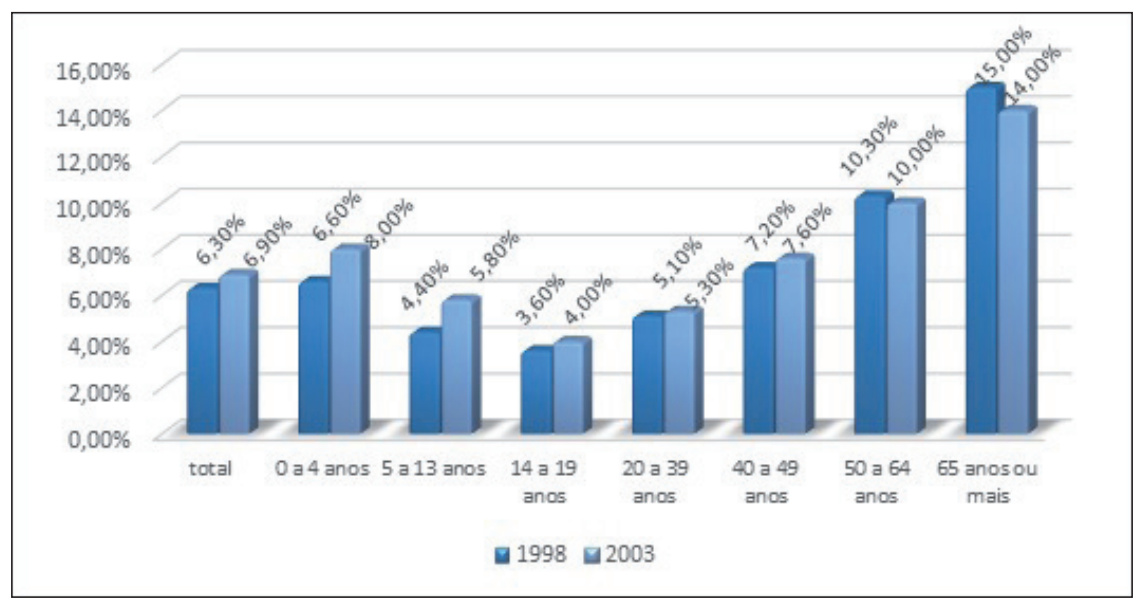

Gráfico 3 - Proporção de pessoas com restrição à atividades rotineiras por motivo de saúde/ PNAD 1998 e 2003.

Fonte: IBGE $(1998,2003)$.

A investigação da prevalência de limitação para as atividades foi direcionada à população com idade igual ou superior a 14 anos. Para cada um dos sete itens destinados a representar as atividades diárias da vida das pessoas foi mensurado o grau de limitação para a realização das mesmas a partir de uma escala ordinal com quatro níveis, variando da ausência de qualquer tipo de limitação até a total impossibilidade para a realização, conforme apresentado no quadro abaixo.

\begin{tabular}{|l|l|}
\hline Componente da avaliação da limitação das atividades & Grau de limitação \\
\hline $\begin{array}{l}\text { Normalmente, por problema de saúde, ...... tem dificuldade para alimentar- } \\
\text {-se, tomar banho ou ir ao banheiro? }\end{array}$ & $\begin{array}{l}\text { Não tem dificuldade } \\
\text { Tem pequena dificuldade } \\
\text { Tem grande dificuldade } \\
\text { Não consegue }\end{array}$ \\
\hline $\begin{array}{l}\text { Normalmente, por problema de saúde, ...... tem dificuldade para correr, } \\
\text { levantar objetos pesados, praticar esportes ou realizar trabalhos pesados? }\end{array}$ & $\begin{array}{l}\text { Não tem dificuldade } \\
\text { Tem pequena dificuldade } \\
\text { Tem grande dificuldade } \\
\text { Não consegue }\end{array}$ \\
\hline $\begin{array}{l}\text { Normalmente, por problema de saúde, ....... tem dificuldade para empurrar } \\
\text { mesa ou realizar consertos domésticos? }\end{array}$ & $\begin{array}{l}\text { Não tem dificuldade } \\
\text { Tem pequena dificuldade } \\
\text { Tem grande dificuldade } \\
\text { Não consegue }\end{array}$ \\
\hline $\begin{array}{l}\text { Normalmente, por problema de saúde, ....... tem dificuldade para subir } \\
\text { ladeira ou escada? }\end{array}$ & $\begin{array}{l}\text { Não tem dificuldade } \\
\text { Tem pequena dificuldade } \\
\text { Tem grande dificuldade }\end{array}$ \\
\hline
\end{tabular}




\begin{tabular}{|l|l|}
\hline $\begin{array}{l}\text { Normalmente, por problema de saúde, ...... tem dificuldade para abaixar-se, } \\
\text { ajoelhar-se ou curvar-se? }\end{array}$ & $\begin{array}{l}\text { Não tem dificuldade } \\
\text { Tem pequena dificuldade } \\
\text { Tem grande dificuldade } \\
\text { Não consegue }\end{array}$ \\
\hline $\begin{array}{l}\text { Normalmente, por problema de saúde, ...... tem dificuldade para andar mais } \\
\text { do que um quilômetro? }\end{array}$ & $\begin{array}{l}\text { Náo tem dificuldade } \\
\text { Tem pequena dificuldade } \\
\text { Tem grande dificuldade }\end{array}$ \\
\hline $\begin{array}{l}\text { Normalmente, por problema de saúde, ...... tem dificuldade para andar cerca } \\
\text { de } 100 \text { metros? }\end{array}$ & $\begin{array}{l}\text { Tem pequena dificuldade } \\
\text { Tem tem dificuldade } \\
\text { Tem grande dificuldade } \\
\text { Não consegue }\end{array}$ \\
\hline
\end{tabular}

QUADRO 1 - Componentes da avaliação da limitação das atividades (características de mobilidade física das pessoas de 14 anos ou mais), PNAD, Suplemento Saúde 1998 e 2003.

Fonte: $\operatorname{IBGE}(1998,2003)$.

Em análise à PNAD 2003 é verificado que 21\% dos respondentes relataram alguma dificuldade para correr, levantar objetos pesados, praticar esportes ou realizar trabalhos pesados, e que 3,5\% informaram não conseguir realizar tais atividades. Entre as atividades avaliadas, esta foi a mais comprometida. Também é possível verificar que $14,4 \%$ e $13,7 \%$ da população, aproximadamente, relataram, respectivamente, alguma limitação para subir ladeira ou escada e para abaixar-se, ajoelhar-se e curvar-se (Tabela 3).

Aproximadamente um quarto da população investigada relatou algum grau de limitação para a realização das atividades investigadas. Em torno de $15 \%$ e $5 \%$ dos entrevistados relataram ter grande dificuldade para realizar ao menos uma das atividades investigadas e não conseguir realizá-las, respectivamente. Para todas as atividades verificadas a prevalência de limitação para as mesmas aumentou com a idade. Para a população compreendida entre os 40 e 59 anos, as prevalências de graus moderados a intensos de limitaçáo foram cerca de três a cinco vezes mais altas do que entre os jovens e adultos jovens, representados pela faixa dos 14 aos 39 anos. $\mathrm{Na}$ faixa dos 60 anos e mais, as prevalências de graus moderados a intensos de limitação se mostraram em torno de 15 a 20 vezes mais elevadas do que as observadas na faixa dos 14 aos 39 anos (Tabela 3).

Estes dadospermitem certas ponderaçóes, sobretudo no que diz respeito à probabilidade de acometimento de deficiências com o advir da idade. Não obstante, elucidam ainda o grande número de pessoas com algum grau de dificuldade para a mobilidade e também revelam uma mudança na atenção a este contexto. 
Tabela 3 - Proporção de brasileiros com 14 anos ou mais com grau de limitação para as atividades investigadas.

\begin{tabular}{|c|c|c|c|c|c|c|c|c|c|}
\hline & Grau de limitação & $\begin{array}{c}14 \text { a } 39 \\
\text { anos }\end{array}$ & $\%$ & $\begin{array}{c}40 \text { a } 59 \\
\text { anos }\end{array}$ & $\%$ & $\begin{array}{c}60 \text { anose } \\
\text { mais }\end{array}$ & $\%$ & Total & $\%$ \\
\hline \multirow{5}{*}{$\begin{array}{l}\text { Normalmente, por } \\
\text { problema de saúde, } \\
\text { tem dificuldade para } \\
\text { alimentar-se, tomar } \\
\text { banho ou irao } \\
\text { banheiro? }\end{array}$} & Nāo tem dificuldade & 168.390 & 98,8 & 77.230 & 96,5 & 32.014 & 86,5 & 277.634 & 96,6 \\
\hline & $\begin{array}{l}\text { Tem pequena } \\
\text { dificuldade }\end{array}$ & 1.331 & 0,8 & 1.895 & 2,4 & 2.618 & 7,1 & 5.844 & 2,0 \\
\hline & $\begin{array}{l}\text { Tem grande difi- } \\
\text { culdade }\end{array}$ & 486 & 0,3 & 687 & 0,9 & 1.485 & 4,0 & 2.658 & 0,9 \\
\hline & Não consegue & 278 & 0,2 & 185 & 0,2 & 874 & 2,4 & 1.337 & 0,5 \\
\hline & Total & 170.485 & 100 & 79.997 & 100 & 36.991 & 100 & 287.473 & 100 \\
\hline \multirow{5}{*}{$\begin{array}{l}\text { Normalmente, por } \\
\text { problema de saúde, } \\
\text { tem dificuldade para } \\
\text { correr, levantar } \\
\text { objetos } \\
\text { pesados, praticar } \\
\text { esportes ou realizar } \\
\text { trabalhos pesados? }\end{array}$} & $\begin{array}{l}\text { Não tem dificul- } \\
\text { dade }\end{array}$ & 154.991 & 91,3 & 56.781 & 71,8 & 12.958 & 37,4 & 224.730 & 79,3 \\
\hline & $\begin{array}{l}\text { Tem pequena } \\
\text { dificuldade }\end{array}$ & 8.958 & 5,3 & 11.039 & 14,0 & 7.751 & 22,4 & 27.748 & 9,8 \\
\hline & $\begin{array}{l}\text { Tem grande difi- } \\
\text { culdade }\end{array}$ & 4.399 & 2,6 & 8.107 & 10,2 & 8.691 & 25,1 & 21.197 &, 5 \\
\hline & Não consegue & 1.374 & 0,8 & 3.198 & 4,0 & 5.232 & 15,1 & 9.804 & 3,5 \\
\hline & Total & 169.722 & 100 & 79.125 & 100 & 34.632 & 100 & 283.479 & 100 \\
\hline \multirow{5}{*}{$\begin{array}{l}\text { Normalmente, por } \\
\text { problema de saúde, } \\
\text { tem dificuldade para } \\
\text { empurrar mesa ou } \\
\text { realizar consertos } \\
\text { domésticos? }\end{array}$} & $\begin{array}{l}\text { Não tem dificul- } \\
\text { dade }\end{array}$ & 164.605 & 97,0 & 69.347 & 87,6 & 21.620 & 62,4 & 255.572 & 90,2 \\
\hline & $\begin{array}{l}\text { Tem pequena } \\
\text { dificuldade }\end{array}$ & 3.517 & 2,1 & 6.238 & 7,9 & 7.410 & 21,4 & 17.165 & 6,1 \\
\hline & $\begin{array}{l}\text { Tem grande difi- } \\
\text { culdade }\end{array}$ & 1.169 & 0,7 & 2.704 & 3,4 & 3.883 & 11,2 & 7.756 & 2,7 \\
\hline & Náo consegue & 431 & 0,3 & 837 & 1,1 & 1.719 & 5,0 & 2.987 & 1,1 \\
\hline & Total & 169.722 & 100 & 79.126 & 100 & 34.632 & 100 & 283.480 & 100 \\
\hline \multirow{5}{*}{$\begin{array}{l}\text { Normalmente, por } \\
\text { problema de saúde, } \\
\text { tem dificuldade para } \\
\text { subir ladeira ou } \\
\text { escada? }\end{array}$} & $\begin{array}{l}\text { Não tem dificul- } \\
\text { dade }\end{array}$ & 161.795 & 95,3 & 63.717 & 80,5 & 16.933 & 48,9 & 242.445 & 85,5 \\
\hline & $\begin{array}{l}\text { Tem pequena } \\
\text { dificuldade }\end{array}$ & 5.395 & 3,2 & 9.004 & 11,4 & 8.357 & 24,1 & 22.756 & 8,0 \\
\hline & $\begin{array}{l}\text { Tem grande difi- } \\
\text { culdade }\end{array}$ & 2.115 & 1,2 & 5.331 & 6,7 & 7.067 & 20,4 & 14.513 & 5,1 \\
\hline & Não consegue & 416 & 0,2 & 1.074 & 1,4 & 2.276 & 6,6 & 3.766 & 1,3 \\
\hline & Total & 169.721 & 100 & 79.126 & 100 & 34.633 & 100 & 283.480 & 100 \\
\hline \multirow{5}{*}{$\begin{array}{l}\text { Normalmente, por } \\
\text { problema de saúde, } \\
\text {...... } \\
\text { tem dificuldade para } \\
\text { abaixar-se, ajoelhar- } \\
\text {-se } \\
\text { ou curvar-se? }\end{array}$} & $\begin{array}{l}\text { Não tem dificul- } \\
\text { dade }\end{array}$ & 162.364 & 95,7 & 64.179 & 81,1 & 18.079 & 52,2 & 244.622 & 86,3 \\
\hline & $\begin{array}{l}\text { Tem pequena } \\
\text { dificuldade }\end{array}$ & 5.292 & 3,1 & 8.992 & 11,4 & 8.373 & 24,2 & 22.657 & 8,0 \\
\hline & $\begin{array}{l}\text { Tem grande difi- } \\
\text { culdade }\end{array}$ & 1.746 & 1,0 & 4.988 & 6,3 & 6.367 & 18,4 & 13.101 & 4,6 \\
\hline & Não consegue & 320 & 0,2 & 967 & 1,2 & 1.813 & 5,2 & 3.100 & 1,1 \\
\hline & Total & 169.722 & 100 & 79.126 & 100 & 34.632 & 100 & 283.480 & 100 \\
\hline
\end{tabular}




\begin{tabular}{|c|c|c|c|c|c|c|c|c|c|}
\hline \multirow{5}{*}{$\begin{array}{l}\text { Normalmente, por } \\
\text { problema de saúde, } \\
\text {...... } \\
\text { tem dificuldade para } \\
\text { andar mais do que } \\
\text { um quilômetro? }\end{array}$} & $\begin{array}{l}\text { Não tem dificul- } \\
\text { dade }\end{array}$ & 163.692 & 96,4 & 68.043 & 86,0 & 20.714 & 59,8 & 252.449 & 89,1 \\
\hline & $\begin{array}{l}\text { Tem pequena } \\
\text { dificuldade }\end{array}$ & 4.013 & 2,4 & 6.374 & 8,1 & 6.349 & 18,3 & 16.736 & 5,9 \\
\hline & $\begin{array}{l}\text { Tem grande difi- } \\
\text { culdade }\end{array}$ & 1.626 & 1,0 & 3,678 & 4,6 & 5.321 & 15,4 & 10.625 & 3,7 \\
\hline & Não consegue & 390 & 0,2 & 1.031 & 1,3 & 2.248 & 6,5 & 3.669 & 1,3 \\
\hline & Total & 169.721 & 100 & 79.126 & 100 & 34.632 & 100 & 283.479 & 100 \\
\hline \multirow{5}{*}{$\begin{array}{l}\text { Normalmente, por } \\
\text { problema de saúde, } \\
\text {...... } \\
\text { tem dificuldade para } \\
\text { andar cerca de } 100 \\
\text { metros? }\end{array}$} & $\begin{array}{l}\text { Não tem dificul- } \\
\text { dade }\end{array}$ & 168.165 & 99,1 & 75.716 & 95,7 & 28.616 & 82,6 & 272.497 & 96,1 \\
\hline & $\begin{array}{l}\text { Tem pequena } \\
\text { dificuldade }\end{array}$ & 1.166 & 0,7 & 2.467 & 3,1 & 3.867 & 11,2 & 7.500 & 2,6 \\
\hline & $\begin{array}{l}\text { Tem grande difi- } \\
\text { culdade }\end{array}$ & 295 & 0,2 & 789 & 1,0 & 1.711 & 4,9 & 2.795 & 1,0 \\
\hline & Não consegue & 95 & 1,0 & 154 & 0,2 & 438 & 1,3 & 687 & 0,2 \\
\hline & Total & 169.721 & 100 & 79.126 & 100 & 34.632 & 100 & 283.479 & 100 \\
\hline
\end{tabular}

Fonte: IBGE $(1998,2003)$.

Embora não haja um direcionamento específico às deficiências graves, estabelecidas, as PNADs de 1998 e 2003 conferem um avanço ao contexto das pesquisas sobre as deficiências. É factível a verificação de que há uma preocupação com a condição da mobilidade e de realizaçấo de tarefas da vida cotidiana. Estes instrumentos conferem sensibilidade para com as dificuldades - que podem ser compreendidas como graus de deficiências - vivenciadas pelas pessoas na realização de tais tarefas.

No Censo Demográfico de 2000 a investigação sobre as deficiências foi implementada de forma mais abrangente, incorporando o conceito de limitação de atividades para identificar deficiências em relação à capacidade de realização, ao comportamento e participação social. $\mathrm{O}$ conceito de base passou a seguir as recomendaçóes internacionais, especialmente a InternationalClassificationofFunctioning, Disabilityand Health (ICF, 2001), elaborada e difundida pela Organização Mundial da Saúde - OMS, a qual inclui diversos níveis de limitação para as atividades e permite distinguir os graus de deficiência para enxergar, ouvir e também para a mobilidade (IBGE, 2003, 2004).

A ampliação do conceito de base para a pesquisa das deficiências no Censo 2000 permitiu um aumento vultuoso do número de pessoas que se declararam com alguma deficiência. Para uma população de 169.872 .856 pessoas, 24.600 .256 pessoas se declararam com algum tipo de deficiência, o que corresponde à $14,3 \%$ da população em 2000. A distribuição da população com deficiência, segundo o tipo da deficiência e grau de severidade, figura na Tabela 4.

A partir deste levantamento é possível verificar que o número total de deficiências é bastante aumentado quando se leva em consideração as dificuldades, e não apenas as incapacidades totais e estabelecidas. Com este novo encaminhamento, tanto o indicativo de "alguma dificuldade", quanto o indicativo de "grande dificuldade", seja para a condição de enxergar, de ouvir ou para a condição da mobilidade, passam a estabelecer uma visão mais clara da dimensão da deficiência. Apenas em referência à números totais, pode-se dizer que o Censo Demográfico 2000 multiplicou por 12 a declaração das pessoas em condição de deficiência, em relação ao 
Censo de 1991. É factível o entendimento de que estes números totais não decorrem do aumento da incidência de deficiências, mas da mudança do conceito de sustentação dos instrumentos de coleta de informaçóes e, consequentemente, dos próprios instrumentos.

Tabela 4 - População por tipo de deficiência segundo sexo.

\begin{tabular}{|c|c|c|c|c|}
\hline & Tipo de deficiência & Total & Homens & Mulheres \\
\hline & & 24600256 & 11420544 & 13179712 \\
\hline \multicolumn{2}{|c|}{ Deficiência mental permanente } & 2844937 & 1545462 & 1299474 \\
\hline \multicolumn{2}{|c|}{ Deficiência física } & 1416060 & 861196 & 554864 \\
\hline \multirow{3}{*}{ 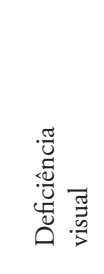 } & Incapaz de enxergar & 148023 & 70160 & 77863 \\
\hline & $\begin{array}{l}\text { Grande dificuldade permanente } \\
\text { de enxergar }\end{array}$ & 2435873 & 1044746 & 1391127 \\
\hline & $\begin{array}{l}\text { Alguma dificuldade permanente } \\
\text { de enxergar }\end{array}$ & 14060946 & 6144168 & 7916778 \\
\hline \multirow{3}{*}{ 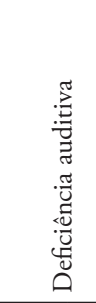 } & Incapaz de ouvir & 166365 & 86431 & 79934 \\
\hline & $\begin{array}{l}\text { Grande dificuldade permanente } \\
\text { de ouvir }\end{array}$ & 883079 & 466043 & 417037 \\
\hline & $\begin{array}{l}\text { Alguma dificuldade permanente } \\
\text { de ouvir }\end{array}$ & 4685655 & 2465745 & 2219910 \\
\hline \multirow{4}{*}{ 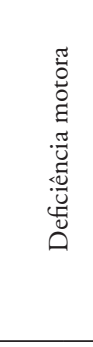 } & Incapaz de caminhar ou subir escada & 574186 & 275301 & 298885 \\
\hline & $\begin{array}{l}\text { Grande dificuldade permanente } \\
\text { de caminhar ou subir escada }\end{array}$ & 1772690 & 739219 & 1033471 \\
\hline & $\begin{array}{l}\text { Alguma dificuldade permanente } \\
\text { de caminhar ou subir escada }\end{array}$ & 5592908 & 2280551 & 3312357 \\
\hline & Nenhuma destas deficiências & 143726947 & 71391433 & 72335514 \\
\hline
\end{tabular}

Fonte: IBGE (2000).

Também é verificada no Censo Demográfico 2000 a proporção de pessoas com pelo menos uma deficiência ouincapacidade segundo os grupos de idade. Os dados apresentam um panorama em que para as crianças de zero a 14 anos de idade, é encontrada uma referência de 4,3\%delas com pelo menos umtipo de incapacidade. Para as pessoas em idade ativa (15 a 64 anos) essa proporção passa para 15,6\%. Já para as pessoas de 65 anos ou mais, mais da metade declararam ser portadoras de alguma deficiência ou incapacidade, conforme apresentado no Gráfico 4. O crescimento da proporção se verifica com o aumento da idade, o que se pressupóe uma consequência do aumento das limitaçóes nas atividades decorrentes do envelhecimento (IBGE, 2003). 


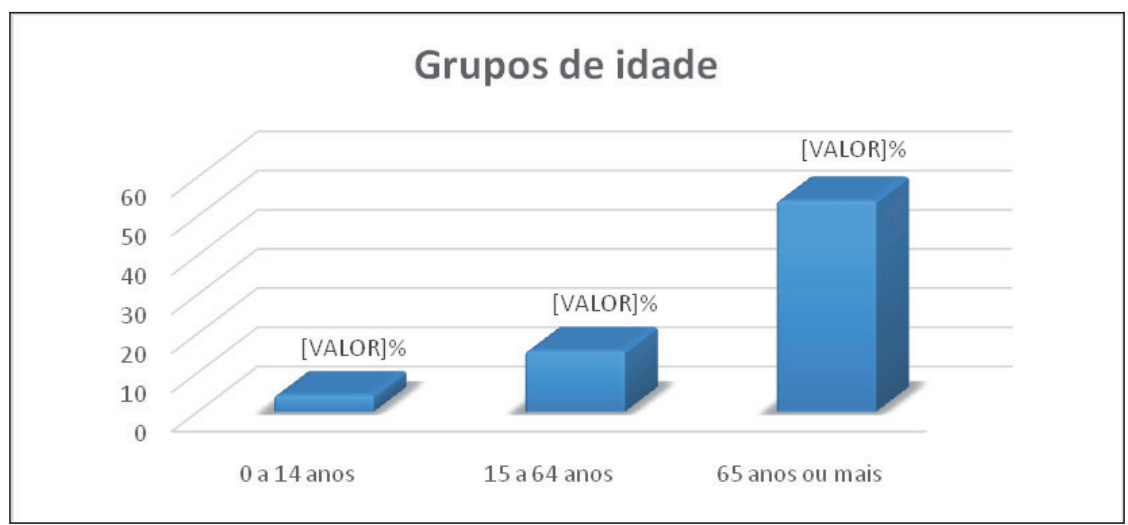

Gráfico 4 - Proporção da população com pelo menos uma das deficiências investigadas, segundo os grandes grupos de idade - Censo 2000.

Fonte: IBGE (2000).

Analisar esta proporção reforça alguns pressupostos de caráter conceitual sobre a deficiência. Sobretudo aqueles que direcionam o entendimento ao fato de que a deficiência é estabelecida na presença de algum grau de dificuldade para a realização de atividades da vida cotidiana. Por este prisma, o aumento da condição de deficiência está relacionado ao aumento da idade. É natural que, à medida que as pessoas envelheçam, aumente a proporção de pessoas com alguma deficiência para enxergar, ouvir e/ou se locomover. Este olhar desmistifica a deficiência, e póe a todos em rota de encontro com a mesma. A idade gera incapacidades e insere a pessoas à condição de deficiente.

O Censo de 2000 apresenta um avanço bastante significativo no levantamento de informaçóes sobre as deficiências. Este Censo se constitui no primeiro instrumento em que se pode verificar uma sensibilidade constatável acerca das deficiências. A atenção para com os graus de dificuldade para enxergar, ouvir e se locomover proporcionam a condição de avaliar o nível de dificuldade para a realização das tarefas cotidianas da vida de todas as pessoas e, consequentemente, da real condição de deficiência.

O Censo Demográfico de 2010 não apenas mantém a extensão de sua investigação a respeito do tema pessoas com deficiência como também faz constar em sua fundamentação teórica as adequaçóes e modificações ocorridas ao longo dos levantamentos censitários, em adequação conceitual ao tema. Os Censos Demográficos, conforme relatado no referencial teórico do Censo 2012, tem se adequado à evolução do conceito de deficiência, que vem se modificando, por sua vez, de forma a acompanhar a maneira como a sociedade se relaciona com a parcela da população que apresenta algum tipo de deficiência (IBGE, 2012).

Dessa forma, a investigação da deficiência no Censo Demográfico, assim como a abordagem da deficiência no contexto social, evoluiu do modelo médico - para o qual somente era considerada a patologia física e o sintoma a ela associado que, em consequência, dava origem a uma incapacidade - para o modelo biopsicosocial, adotado pela OMS e estruturado na Classificação Internacional de Funcionalidade, Incapacidade e Saúde - CIF (IBGE, 2012). 
Com base nesta classificação, toda dificuldade ou limitação corporal, permanente ou temporária, é passível de ser classificada como deficiência.

Assumir este vínculo ao entendimento internacional a respeito do tema pessoas com deficiência, de forma documental, credita a este Censo um caráter de maior sensibilidade ao tema, em relação aos outros que o antecederam. Se o Censo de 2000 se constituiu no primeiro instrumento em que se pôde verificar uma sensibilidade constatável acerca das deficiências, o Censo de 2010 incorpora uma maior sensibilidade em relação também às pessoas com deficiência. A terminologia empregada também é alterada. Enquanto no Censo de 2000 o termo utilizado foi "pessoas portadoras de deficiência", no Censo de 2010 o termo usado foi "pessoas com deficiência”, o que denota adequação ao consenso universal para referência ao tema, nos dias de hoje.

Essa adequação, assim como já acorreu no Censo de 2000, em razão de promover um levantamento bastante amplo acerca das deficiências credita aos resultados do Censo Demográfico de 2010 um número bastante grande de pessoas que declararam ter pelo menos uma das deficiências investigadas. Os resultados apontaram 45.606 .048 milhóes de pessoas com algum tipo de deficiência, o que corresponde a $23,9 \%$ da população brasileira, que era de 190.755.799 milhóes de pessoas.

A distribuição da população com deficiência, segundo o tipo da deficiência e grau de severidade, e também detalhados em razão do sexo pode ser acompanhada na Tabela 5.

Tabela 5 - População residente, por tipo de deficiência, segundo o sexo e os grupos de idade Brasil - 2010 .

\section{Populaçáo residente}

Tipo de deficiência

\begin{tabular}{|c|c|c|c|c|c|c|c|c|}
\hline \multirow[t]{2}{*}{$\begin{array}{l}\text { Sexo e grupos } \\
\text { de idade }\end{array}$} & \multirow{2}{*}{ Total (1) (2) } & \multirow{2}{*}{$\begin{array}{l}\text { Pelo menos } \\
\text { uma das } \\
\text { deficiências } \\
\text { investigadas } \\
\text { (1) }\end{array}$} & \multicolumn{3}{|c|}{ Visual } & \multicolumn{3}{|c|}{ Auditiva } \\
\hline & & & $\begin{array}{l}\text { Não } \\
\text { consegue } \\
\text { de modo } \\
\text { algum }\end{array}$ & $\begin{array}{l}\text { Grande } \\
\text { dificuldade }\end{array}$ & $\begin{array}{l}\text { Alguma } \\
\text { dificuldade }\end{array}$ & $\begin{array}{l}\text { Não } \\
\text { consegue } \\
\text { de modo } \\
\text { algum }\end{array}$ & $\begin{array}{l}\text { Grande difi- } \\
\text { culdade }\end{array}$ & $\begin{array}{l}\text { Alguma } \\
\text { dificuldade }\end{array}$ \\
\hline Total & 190755799 & 45606048 & 506377 & 6056533 & 29211482 & 344206 & 1798967 & 7574145 \\
\hline 0 a 4 anos & 13806733 & 385303 & 20935 & 24707 & 122581 & 13593 & 10996 & 54453 \\
\hline 5 a 9 anos & 14967767 & 1147368 & 21407 & 97719 & 670799 & 16494 & 31976 & 184925 \\
\hline 10 a 14 anos & 17167135 & 1926730 & 24058 & 175176 & 1286971 & 22379 & 45914 & 235471 \\
\hline 15 a 19 anos & 16986788 & 2017529 & 24457 & 195493 & 1357295 & 24836 & 44564 & 219824 \\
\hline 15 a 17 anos & 10353865 & 1218607 & 14475 & 117495 & 821618 & 14373 & 27442 & 133384 \\
\hline 18 e 19 anos & 6632922 & 798921 & 9981 & 77998 & 535677 & 10463 & 17122 & 86439 \\
\hline 20 a 24 anos & 17240864 & 2215799 & 29808 & 210571 & 1473070 & 30591 & 48795 & 255109 \\
\hline 25 a 29 anos & 17102917 & 2376938 & 35860 & 232451 & 1540445 & 31146 & 53492 & 288966 \\
\hline 30 a 34 anos & 15744616 & 2447685 & 34986 & 235409 & 1523122 & 30538 & 63894 & 325833 \\
\hline 35 a 39 anos & 13888191 & 2590841 & 32346 & 258624 & 1604547 & 26753 & 70325 & 362784 \\
\hline 40 a 44 anos & 13008496 & 3797150 & 31166 & 438135 & 2642127 & 23843 & 85537 & 444978 \\
\hline 45 a 49 anos & 11834647 & 4763491 & 31233 & 617095 & 3481074 & 18724 & 97630 & 529426 \\
\hline 50 a 54 anos & 10134322 & 4705129 & 28184 & 655232 & 3337231 & 17408 & 119958 & 625726 \\
\hline 55 a 59 anos & 8284433 & 4170185 & 28068 & 605386 & 2819567 & 15520 & 130589 & 668086 \\
\hline
\end{tabular}




\begin{tabular}{|c|c|c|c|c|c|c|c|c|}
\hline 60 a 64 anos & 6503287 & 3524275 & 25855 & 527765 & 2258647 & 13267 & 141022 & 686776 \\
\hline 65 a 69 anos & 4852789 & 2894694 & 24058 & 458022 & 1748246 & 11925 & 147136 & 678305 \\
\hline 70 a 74 anos & 3744738 & 2451628 & 23652 & 426442 & 1381745 & 10571 & 164179 & 669689 \\
\hline 75 a 79 anos & 2570686 & 1839631 & 24466 & 353344 & 947089 & 10000 & 169752 & 561265 \\
\hline $\begin{array}{l}80 \text { anos ou } \\
\text { mais }\end{array}$ & 2917391 & 2351671 & 65840 & 544962 & 1016924 & 26618 & 373207 & 782529 \\
\hline Homens & 93406990 & 19805367 & 237538 & 2437398 & 12244750 & 172405 & 946289 & 3789918 \\
\hline 0 a 4 anos & 7025701 & 204414 & 10966 & 13615 & 62007 & 7149 & 6091 & 30423 \\
\hline 5 a 9 anos & 7623609 & 585371 & 11203 & 49945 & 319125 & 8932 & 18385 & 101599 \\
\hline 10 a 14 anos & 8727095 & 905501 & 11861 & 84023 & 559843 & 11905 & 26043 & 123606 \\
\hline 15 a 19 anos & 8557608 & 883678 & 12316 & 91141 & 539345 & 13095 & 25127 & 107356 \\
\hline 15 a 17 anos & 5224763 & 534488 & 7232 & 54869 & 327421 & 7693 & 15520 & 65277 \\
\hline 18 e 19 anos & 3332845 & 349189 & 5084 & 36273 & 211924 & 5402 & 9607 & 42079 \\
\hline 20 a 24 anos & 8627665 & 977292 & 14572 & 93804 & 590890 & 15845 & 26543 & 127308 \\
\hline 25 a 29 anos & 8458790 & 1049229 & 17355 & 99676 & 616891 & 15403 & 29422 & 151291 \\
\hline 30 a 34 anos & 7718081 & 1076432 & 17186 & 100062 & 603831 & 15430 & 35579 & 170210 \\
\hline 35 a 39 anos & 6767177 & 1101613 & 15469 & 103265 & 612402 & 13435 & 38768 & 190563 \\
\hline 40 a 44 anos & 6319971 & 1560642 & 15088 & 158526 & 1016168 & 12139 & 46693 & 229436 \\
\hline 45 a 49 anos & 5692722 & 2051993 & 14360 & 234504 & 1477345 & 9122 & 52527 & 268472 \\
\hline 50 a 54 anos & 4825839 & 2074495 & 13424 & 254354 & 1475568 & 8953 & 65722 & 318749 \\
\hline 55 a 59 anos & 3912544 & 1843384 & 13217 & 237719 & 1253680 & 7795 & 72209 & 345866 \\
\hline 60 a 64 anos & 3033130 & 1541658 & 12159 & 209839 & 988008 & 6224 & 79405 & 352352 \\
\hline 65 a 69 anos & 2224862 & 1255930 & 10942 & 184772 & 756586 & 6135 & 82784 & 345276 \\
\hline 70 a 74 anos & 1675553 & 1046548 & 11127 & 173494 & 587242 & 5239 & 89121 & 336161 \\
\hline 75 a 79 anos & 1089024 & 755860 & 11069 & 141432 & 391289 & 4826 & 87561 & 265684 \\
\hline $\begin{array}{l}80 \text { anos ou } \\
\text { mais }\end{array}$ & 1127619 & 891330 & 25222 & 207226 & 394531 & 10777 & 164309 & 325566 \\
\hline Mulheres & 97348809 & 25800681 & 268839 & 3619135 & 16966732 & 171801 & 852678 & 3784228 \\
\hline 0 a 4 anos & 6781032 & 180889 & 9968 & 11093 & 60574 & 6445 & 4905 & 24030 \\
\hline 5 a 9 anos & 7344159 & 561998 & 10204 & 47774 & 351675 & 7561 & 13592 & 83326 \\
\hline 10 a 14 anos & 8440040 & 1021229 & 12197 & 91153 & 727129 & 10473 & 19870 & 111866 \\
\hline 15 a 19 anos & 8429180 & 1133851 & 12141 & 104352 & 817950 & 11741 & 19438 & 112468 \\
\hline 15 a 17 anos & 5129102 & 684119 & 7244 & 62626 & 494197 & 6680 & 11923 & 68107 \\
\hline 18 e 19 anos & 3300078 & 449732 & 4897 & 41726 & 323753 & 5061 & 7515 & 44360 \\
\hline 20 a 24 anos & 8613199 & 1238507 & 15235 & 116767 & 882180 & 14746 & 22253 & 127801 \\
\hline 25 a 29 anos & 8644127 & 1327710 & 18504 & 132775 & 923554 & 15742 & 24070 & 137676 \\
\hline 30 a 34 anos & 8026535 & 1371254 & 17800 & 135347 & 919291 & 15108 & 28316 & 155622 \\
\hline 35 a 39 anos & 7121014 & 1489229 & 16877 & 155359 & 992145 & 13318 & 31557 & 172222 \\
\hline 40 a 44 anos & 6688525 & 2236509 & 16078 & 279609 & 1625959 & 11704 & 38843 & 215542 \\
\hline 45 a 49 anos & 6141925 & 2711498 & 16872 & 382591 & 2003729 & 9601 & 45102 & 260953 \\
\hline 50 a 54 anos & 5308482 & 2630634 & 14760 & 400878 & 1861663 & 8455 & 54236 & 306977 \\
\hline 55 a 59 anos & 4371889 & 2326801 & 14851 & 367667 & 1565887 & 7726 & 58379 & 322221 \\
\hline 60 a 64 anos & 3470156 & 1982617 & 13696 & 317926 & 1270640 & 7043 & 61617 & 334424 \\
\hline 65 a 69 anos & 2627927 & 1638764 & 13116 & 273250 & 991660 & 5790 & 64352 & 333028 \\
\hline 70 a 74 anos & 2069185 & 1405080 & 12524 & 252948 & 794503 & 5332 & 75059 & 333528 \\
\hline 75 a 79 anos & 1481662 & 1083770 & 13397 & 211911 & 555800 & 5174 & 82191 & 295581 \\
\hline $\begin{array}{l}80 \text { anos ou } \\
\text { mais }\end{array}$ & 1789772 & 1460341 & 40618 & 337736 & 622393 & 15842 & 208898 & 456964 \\
\hline
\end{tabular}


Tabela 5 - População residente, por tipo de deficiência, segundo o sexo e os grupos de idade - Brasil - 2010. (continua)

\begin{tabular}{|c|c|c|c|c|c|}
\hline \multirow{4}{*}{ Sexo e grupos de idade } & \multicolumn{5}{|c|}{ População residente } \\
\hline & \multicolumn{5}{|c|}{ Tipo de deficiência } \\
\hline & \multicolumn{3}{|c|}{ Motora } & \multirow{2}{*}{ Mental / intelectual } & \multirow{2}{*}{$\begin{array}{l}\text { Nenhuma dessas } \\
\text { deficiências (3) }\end{array}$} \\
\hline & $\begin{array}{l}\text { Náo consegue de } \\
\text { modo algum }\end{array}$ & Grande dificuldade & Alguma dificuldade & & \\
\hline Total & 734421 & 3698929 & 8832249 & 2611536 & 145084976 \\
\hline 0 a 4 anos & 57388 & 23189 & 60495 & 64977 & 13419477 \\
\hline 5 a 9 anos & 30152 & 27723 & 81772 & 137140 & 13818227 \\
\hline 10 a 14 anos & 30396 & 34179 & 108120 & 189149 & 15237845 \\
\hline 15 a 19 anos & 28334 & 36892 & 126464 & 186291 & 14966031 \\
\hline 15 a 17 anos & 16974 & 22413 & 73681 & 113474 & 9133549 \\
\hline 18 e 19 anos & 11360 & 14479 & 52783 & 72817 & 5832482 \\
\hline 20 a 24 anos & 29728 & 45942 & 163937 & 188606 & 15016938 \\
\hline 25 a 29 anos & 30111 & 59513 & 214933 & 191943 & 14715518 \\
\hline 30 a 34 anos & 30249 & 84790 & 292220 & 194724 & 13287819 \\
\hline 35 a 39 anos & 27383 & 117304 & 372978 & 185380 & 11290507 \\
\hline 40 a 44 anos & 28102 & 169095 & 535289 & 199102 & 9205527 \\
\hline 45 a 49 anos & 27529 & 245678 & 712135 & 195654 & 7066676 \\
\hline 50 a 54 anos & 29657 & 331081 & 890583 & 183474 & 5425649 \\
\hline 55 a 59 anos & 32728 & 378372 & 975820 & 157493 & 4111740 \\
\hline 60 a 64 anos & 34945 & 382901 & 981815 & 125996 & 2977236 \\
\hline 65 a 69 anos & 40186 & 371513 & 914327 & 96769 & 1957073 \\
\hline 70 a 74 anos & 49565 & 389803 & 848985 & 88423 & 1292634 \\
\hline 75 a 79 anos & 58577 & 365769 & 676582 & 81905 & 730605 \\
\hline 80 anos ou mais & 169392 & 635183 & 875794 & 144510 & 565475 \\
\hline Homens & 342527 & 1372177 & 3264913 & 1409597 & 73558248 \\
\hline 0 a 4 anos & 30202 & 11885 & 32440 & 37159 & 6820525 \\
\hline 5 a 9 anos & 16278 & 15446 & 43122 & 85602 & 7037101 \\
\hline 10 a 14 anos & 16770 & 18371 & 52840 & 116301 & 7820326 \\
\hline 15 a 19 anos & 16023 & 19356 & 54029 & 114085 & 7672216 \\
\hline 15 a 17 anos & 9528 & 11466 & 31365 & 69481 & 4689526 \\
\hline 18 e 19 anos & 6495 & 7890 & 22664 & 44604 & 2982690 \\
\hline 20 a 24 anos & 16582 & 25009 & 74566 & 114635 & 7644341 \\
\hline 25 a 29 anos & 16924 & 30744 & 96251 & 115235 & 7401409 \\
\hline 30 a 34 anos & 16901 & 41111 & 123412 & 113833 & 6635050 \\
\hline 35 a 39 anos & 14909 & 52524 & 149126 & 103810 & 5660673 \\
\hline 40 a 44 anos & 14978 & 72377 & 203050 & 106138 & 4755388 \\
\hline 45 a 49 anos & 14858 & 97471 & 252182 & 100700 & 3637563 \\
\hline 50 a 54 anos & 15530 & 123993 & 306585 & 91686 & 2749122 \\
\hline 55 a 59 anos & 17047 & 139075 & 342714 & 79150 & 2067714 \\
\hline 60 a 64 anos & 17795 & 137719 & 347305 & 61513 & 1490408 \\
\hline
\end{tabular}




\begin{tabular}{|c|c|c|c|c|c|}
\hline 65 a 69 anos & 19511 & 127675 & 326040 & 46830 & 968391 \\
\hline 70 a 74 anos & 22952 & 132265 & 305365 & 40601 & 628795 \\
\hline 75 a 79 anos & 23440 & 120953 & 243195 & 34392 & 333000 \\
\hline 80 anos ou mais & 51830 & 206205 & 312693 & 47927 & 236225 \\
\hline Mulheres & 391894 & 2326752 & 5567335 & 1201938 & 71526728 \\
\hline 0 a 4 anos & 27186 & 11304 & 28055 & 27818 & 6598952 \\
\hline 5 a 9 anos & 13874 & 12277 & 38650 & 51537 & 6781125 \\
\hline 10 a 14 anos & 13626 & 15809 & 55279 & 72847 & 7417519 \\
\hline 15 a 19 anos & 12311 & 17536 & 72435 & 72206 & 7293814 \\
\hline 15 a 17 anos & 7446 & 10947 & 42317 & 43993 & 4444023 \\
\hline 18 e 19 anos & 4865 & 6589 & 30119 & 28213 & 2849792 \\
\hline 20 a 24 anos & 13145 & 20933 & 89371 & 73971 & 7372596 \\
\hline 25 a 29 anos & 13187 & 28769 & 118682 & 76708 & 7314108 \\
\hline 30 a 34 anos & 13349 & 43680 & 168808 & 80891 & 6652769 \\
\hline 35 a 39 anos & 12474 & 64781 & 223853 & 81570 & 5629834 \\
\hline 40 a 44 anos & 13124 & 96718 & 332239 & 92964 & 4450139 \\
\hline 45 a 49 anos & 12671 & 148207 & 459954 & 94954 & 3429113 \\
\hline 50 a 54 anos & 14127 & 207088 & 583998 & 91788 & 2676527 \\
\hline 55 a 59 anos & 15681 & 239297 & 633106 & 78343 & 2044026 \\
\hline 60 a 64 anos & 17151 & 245182 & 634510 & 64482 & 1486828 \\
\hline 65 a 69 anos & 20676 & 243839 & 588287 & 49939 & 988682 \\
\hline 70 a 74 anos & 26614 & 257538 & 543620 & 47822 & 663839 \\
\hline 75 a 79 anos & 35137 & 244816 & 433387 & 47512 & 397605 \\
\hline 80 anos ou mais & 117562 & 428978 & 563101 & 96584 & 329250 \\
\hline
\end{tabular}

Fonte: IBGE (2010).

(1) As pessoas incluídas em mais de um tipo de deficiência foram contadas apenas uma vez.

(2) Inclusive as pessoas sem declaração destas deficiências.

(3) Inclusive a população sem qualquer tipo de deficiência

Tabela 5 - Populaçáo residente, por tipo de deficiência, segundo o sexo e os grupos de idade - Brasil - 2010. (conclusão)

Em relação à proporção de pessoas com pelo menos uma das deficiências investigadas, aqui também em razãodos grupos três grandes grupos de idade, como apresentado no Censo de 2000, e que é o padrão adotado pelo IBGE na análise dos resultados, constatou-se que $7,5 \%$ das crianças de 0 a 14 anos de idade apresentaram pelo menos um tipo de deficiência. Para a populaçáo de 15 a 64 anos de idade a prevalênciade pelo menos uma das deficiências investigadas foi de $24,9 \%$.E para a populaçáo de 65 anos ou mais de idade a prevalência de pelo menos uma das deficiências investigadas foi de $67,7 \%$, perfazendo, em seu total, mais da metade desta populaçáo (Gráfico 5). 


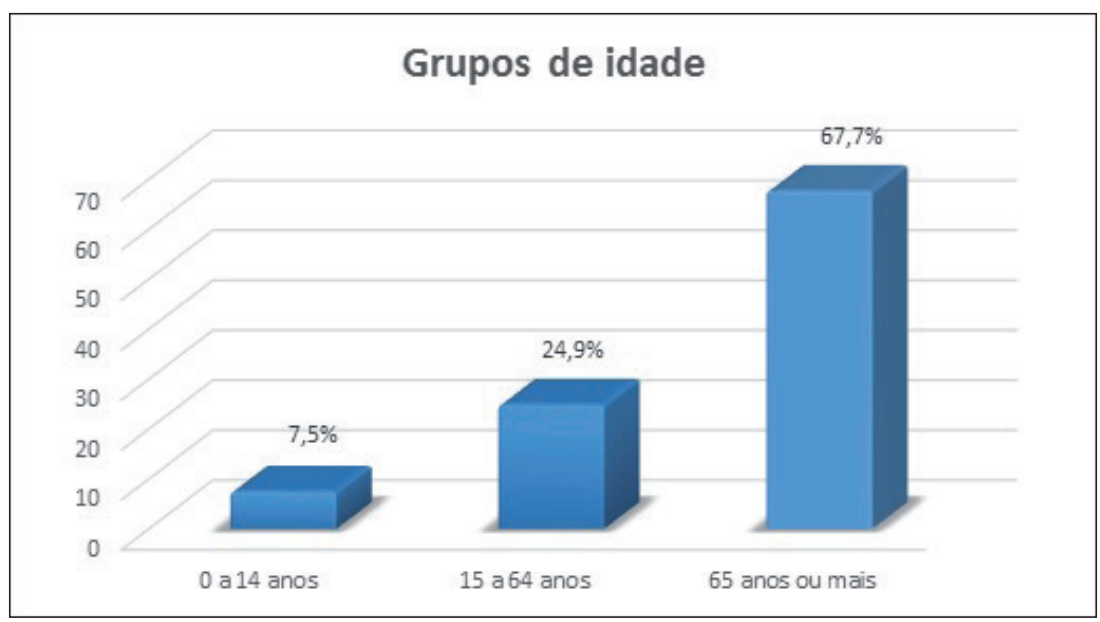

Gráfico 5 - Proporção da população com pelo menos uma das deficiências investigadas, segundo os grandes grupos de idade - Censo 2010.

Fonte: IBGE (2010).

Estes números são bastante semelhantes aos registrados pelo Censo de 2000 no que diz respeito à diferença percentual entre os grupos de idade para a prevalência de pelo menos uma das deficiências investigadas. Contudo, é verificado um aumento da incidência de pelo menos uma das deficiências investigadas em todos os grupos de idade. Não obstante, como naquele Censo, esse aumento proporcional da prevalência de deficiência em relação à idade, faz-se seguro dizer, advém das limitaçóes impostas pelo fenômeno do envelhecimento, situação para a qual há uma perda gradual da acuidade visual e auditiva, assim comotambém da capacidade motora do indivíduo(IBGE, 2012).

\section{CONSIDERAÇÓES FINAIS}

A partir desse mapeamento empírico é possível destacar certo avanço em termos de investigação e abordagem da deficiência. Os censos realizados no Brasilalternaram em informaçôes investigadase detalhamento da deficiência ao longo dos períodos.As mudanças verificadas nos recenseamentos acompanharam a evolução conceitual de deficiência. Essa evolução foi ajustada mediante conquistas sociaisna área do direito à vida e à igualdade de condiçóes, dapolítica de acessibilidade e ainda do interessepela qualidade de vida das pessoas com deficiência.

É preciso reconhecer esses avançose as mudanças sociais que legitimam essa evolução. Mas é preciso também saber que essa evolução não assegura, ainda, que as pessoas com deficiência estejam plenamente acolhidas pela defesa dos seus direitos. Neste sentido, é um segmento que carece de contínuaanálise crítica, inclusive de outros elementos que interferem no planejamentoe assistência a essa parcela da sociedade, que frequentemente não é amparada pelo Estado.

Em síntese, o foco principal desta revisão foi verificar a atenção dadaàs pessoas com deficiência, identificando, durante o decorrer dos tempos, como foram tratadas pelos instru- 
mentos de levantamento populacional; lembrando que estes instrumentos inferem dados para políticas públicas e ações sociais.

A atenção mais sistematizada veio a partir de mudanças conceituais a respeito da deficiência, sobretudo com o modelo social da deficiência. Conjuntamente a essas mudanças, mudou também o olhar sobre as deficiências; e vem mudando a respeito das pessoas com deficiência.

Essa mudança de olhar também permitiu compreender que o universo das deficiências é bem mais amplo que anteriormente se enxergava.

Esse novo prisma ainda encerra dois aspectos importantes: a sociedade é responsável - ao não se adequar às desigualdades - pela criação social da deficiência; e é também responsável por garantir a acessibilidade de 45.606.048 milhóes de pessoas com algum tipo de deficiência, o que corresponde a $23,9 \%$ da população brasileira.

\section{REFERÊNCIAS}

BRASIL. MINISTÉRIO DA AGRICULTURA, I. E. C. Recenseamento de 1920 - 4o. Censo geral da população do Brasil, 1o. da agricultura e das indústrias e 11o. da população da cidade do Rio de Janeiro (Distrito Federal). Rio de Janeiro: Diretoria Geral de Estatística, 1923.

. Recenseamento de 1920. Rio de Janeiro: TYP da Estatística, 1928.

CHAGAS, A. M. D. R.; VIOTTI, R. B. Retrato da pessoa com deficiência no Brasil segundo o Censo de 1991. Brasília, DF: IPEA, 2003.

IBGE. Recenseamento geral do Brasil - 1940. Rio de Janeiro: Serviço Gráfico do Instituto Brasileiro de Geografia e Estatística, 1950.

IBGE. Censo demográfico de 1991. Rio de Janeiro: Diretoria de Pesquisas-IBGE, 1992.

IBGE. Pesquisa nacional por amostra de domicílios - acesso e utilização de serviços de saúde 1998. Rio de Janeiro: IBGE, 2000.

IBGE. Censo demográfico 2000 - características gerais da população. Rio de Janeiro: IBGE, 2003.

IBGE. Tendências demográficas - uma análise dos resultados da amostra do censo demográfico 2000. Rio de Janeiro: IBGE, 2004.

IBGE. Pesquisa nacional por amostra de domicílios - suplemento saúde, 2003. Rio de Janeiro: IBGE, 2005.

IBGE. Censo demográfico 2010 - características gerais da população, religião e pessoas com deficiência. Rio de Janeiro: IBGE, 2012.

MEDEIROS, M.; DINIZ, D. Envelhecimento e deficiência. In: CAMARANO, A. A. (Org.). Os novos idosos brasileiros: muito além dos 60? Rio de Janeiro: IPEA, 2004.

MORRIS, J. Impairment and disability: constructing an ethics of care that promotes human rights. Hypatia, v.16, n.4, p.1-16, 2001.

NERI, M. et al. Retratos da deficiência no Brasil. Rio de Janeiro: FGV/IBRE, CPS, 2003.

Recebido em: 19/12/2013

Reformulado em: 01/03/2015

Aprovado em: 03/03/2015 
CANTORANI, J.R.H. et al. 